\title{
EFFECT OF MICROSTRUCTURAL ORIENTATION ON THE STRESS CORROSION BEHAVIOUR OF PEARLITIC STEEL
}

\author{
J. Toribio and E. Ovejero \\ Department of Materials Science, University of La Coruña \\ E.T.S.I. Caminos, Campus de Elviña, 15192 La Coruña, Spain \\ Tel: (34-981) 167000; Fax: (34-981) 167170
}

\begin{abstract}
This paper deals with the macroscopic effects of microstructural orientation produced by cold drawing on a high-strength pearlitic steel wire. The manufacture process produces a preferential orientation of the pearlitic microstructure at the two levels (colonies and lamellae) which become aligned quasi-parallel to the cold drawing direction, resulting in strength anisotropy of the steel in the matter of fracture behaviour in air and in a corrosive environment (stress corrosion cracking). It is shown that in heavily drawn steel wires an initially transverse crack changes its propagation path to approach the cold drawing direction. A micromechanical model is proposed to explain this behaviour, on the basis of the clear relationship between the angles of microstructural orientation (linked with the pearlite colonies and lamellae) and the deflection angles of the macroscopic crack in wires with different degrees of cold drawing.
\end{abstract}

\section{KEYWORDS:}

Cold drawing, pearlitic steel, microstructural orientation, stress corrosion cracking, hydrogen assisted cracking, localized anodic dissolution, manufacture-induced anisotropy.

\section{INTRODUCTION}

High-strength prestressing steel wires are manufactured by cold drawing to increase both the yield strength and the ultimate tensile strength (UTS) of the steel and allow it to be used as the main constituent of prestressed concrete structural elements. The manufacture technique consisting of progressive drawing of pearlitic wires through a series of dies with diameters 
progressively thinner produces important microstructural changes in the material which could influence its posterior fracture behaviour and stress corrosion performance $/ 1,2 /$. As a matter of fact, clear evidence exists in the scientific literature showing the anisotropic fracture behaviour of prestressing steel in air $/ 3,4 /$, as well as in aggressive environments promoting stress corrosion cracking (SCC) in the material /5-7/.

This paper offers a materials science approach to the modelling of SCC behaviour of cold drawn prestressing steel wires. The approach is based on linking the microstructure of the steels (progressively oriented as a consequence of the manufacture process by cumulative cold drawing) with their macroscopic SCC behaviour (increasingly anisotropic as the degree of cold drawing increases).

\section{MATERIALS}

The materials used in this work were high-strength steels taken from a real manufacturing process. Wires with different degrees of cold drawing were obtained by stopping the manufacturing chain and taking samples from the intermediate stages. The different steels were named with digits 0 to 6 which indicate the number of cold drawing steps undergone, so steel 0 is the hot rolled bar (base material) which is not cold drawn at all, and steel 6 represents the prestressing steel wire (final commercial product) which has suffered six cold drawing steps with progressive reduction of diameter and increase of both yield strength and ultimate tensile strength (UTS). Table 1 shows the chemical composition common to all steels, and Table 2 includes the diameter $\left(D_{i}\right)$, the degree of cold drawing (represented by the ratio of the diameter of any steel wire to the initial diameter before cold drawing $\left.\mathrm{D}_{\mathrm{i}} / \mathrm{D}_{\mathrm{o}}\right)$, the yield strength $\left(\sigma_{02}\right)$ and the ultimate tensile strength (UTS) of the steels. There is a clear improvement of (traditional) mechanical properties as the cold drawing proceeds. However, the consequences of this manufacture technique from the point of view of the fracture and SCC performance of the steels are not well known and require further research. 
TABLE 1

Chemical composition (wt \%) of the steel.

\begin{tabular}{cccccccc}
\hline $\mathrm{C}$ & $\mathrm{Mn}$ & $\mathrm{Si}$ & $\mathrm{P}$ & $\mathrm{S}$ & $\mathrm{Cr}$ & $\mathrm{V}$ & $\mathrm{Al}$ \\
\hline 0.80 & 0.69 & 0.23 & 0.012 & 0.009 & 0.265 & 0.060 & 0.004 \\
\hline
\end{tabular}

TABLE 2

Diameter $\left(D_{i}\right)$, degree of cold drawing $\left(D_{i} / D_{0}\right)$, yield strength $\left(\sigma_{02}\right)$ and UTS of the wires.

\begin{tabular}{lccccccc} 
Steel & 0 & 1 & 2 & 3 & 4 & 5 & 6 \\
\hline $\mathrm{Di}(\mathrm{mm})$ & 12.00 & 10.80 & 9.75 & 8.90 & 8.15 & 7.50 & 7.00 \\
$\mathrm{Di} / \mathrm{D}_{0}$ & 1 & 0.90 & 0.81 & 0.74 & 0.68 & 0.62 & 0.58 \\
$\mathrm{\sigma}_{02}(\mathrm{GPa})$ & 0.686 & 1.100 & 1.157 & 1.212 & 1.239 & 1.271 & 1.506 \\
$\mathrm{UTS}(\mathrm{GPa})$ & 1.175 & 1.294 & 1.347 & 1.509 & 1.521 & 1.526 & 1.762
\end{tabular}

\section{MICROSTRUCTURAL EVOLUTION WITH COLD DRAWING}

Metallographic techniques /8,9/ were applied to reveal the pearlitic microstructure of the progressively drawn steels. Attention was paid to the evolution with cold drawing of the two basic microstructural levels: the pearlite colonies (first microstructural level) and the pearlitic lamellae (second microstructural level). Longitudinal ( $\mathrm{L}$ ) and transverse (T) sections were prepared from all steel wires and mounted to undergo four grinding stages, from 320 to 1200 grit, and three polishing passes followed by etching in Nital $2 \%$. The pearlite colonies were observed by optical microscopy, whereas scanning electron microscopy was required to resolve the lamellar structure of the pearlite. Micrographs were taken always axially oriented for the longitudinal cut and radially oriented for the transverse one.

With regard to the first microstructural level, Fig. 1 shows the optical micrographs of two 

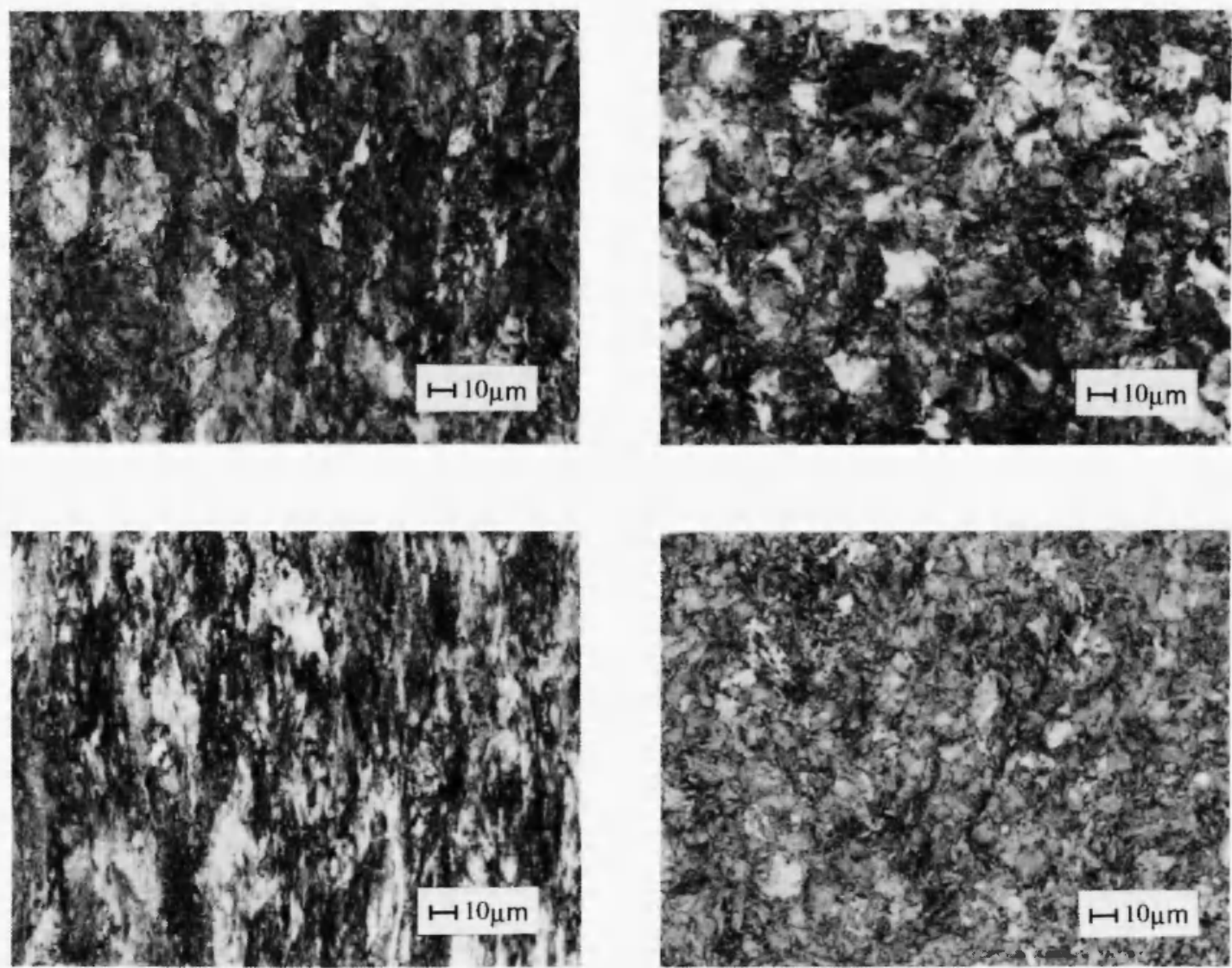

Fig. 1. Optical micrographs of steels 1 (up) and 5 (down), showing the pearlite colonies or first microstructural level. Left side: longitudinal sections. Right side: transverse sections.

different stages of the cold drawing process where an increasing deformation (slenderizing) is observed in the colonies, which determines their angle in relation to the axis. At the same time, a progressive orientation of the colonies in the cold drawing direction (wire axis) can be seen in the longitudinal metallographic sections, whereas the transverse sections show a randomlyoriented appearance at all stages.

In the matter of the second microstructural level, Fig. 2 shows the scanning electron micrographs of two different stages of the cold drawing process where an increasing closeness 

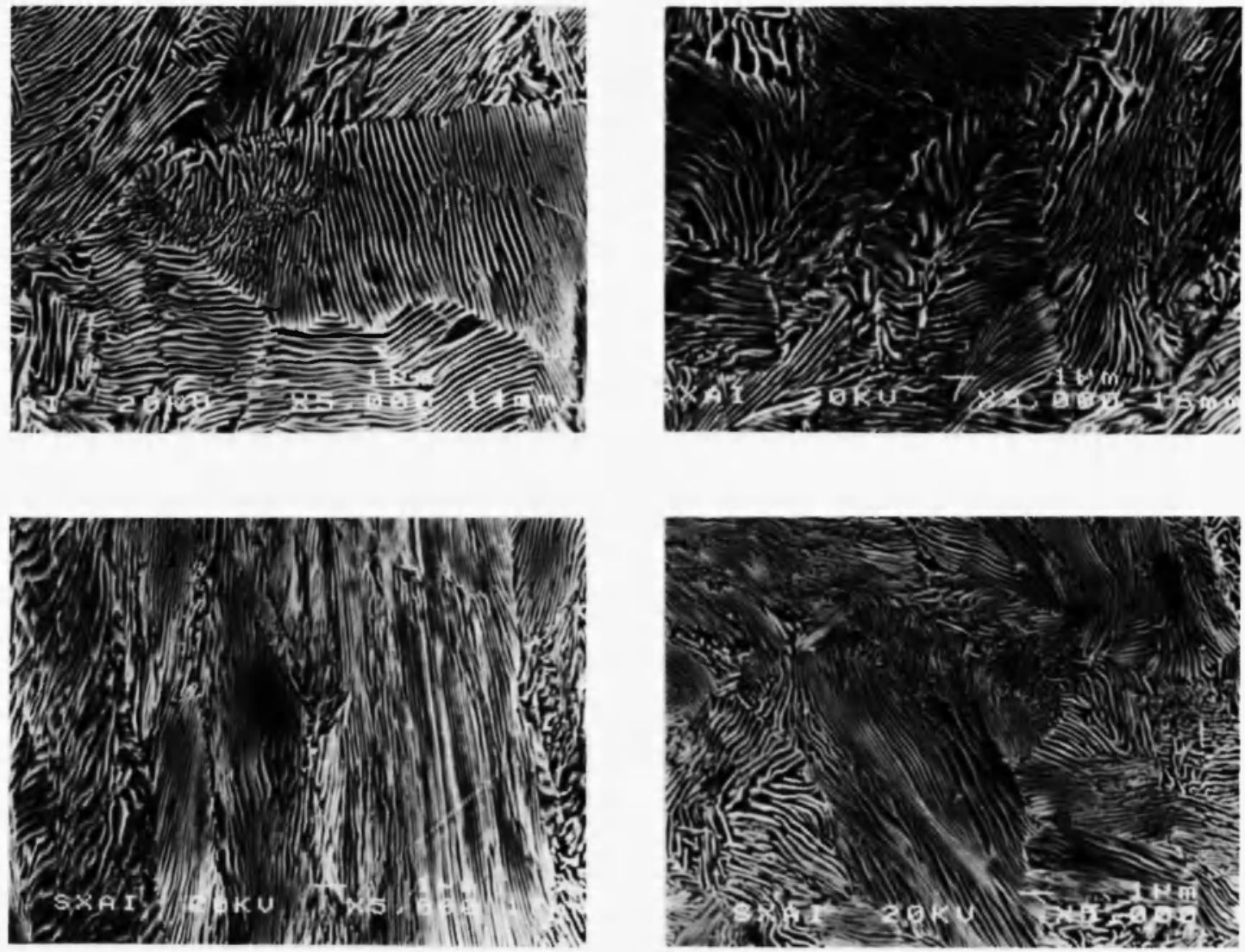

Fig. 2. Scanning electron micrographs of steels 1 (up) and 5 (down), showing the pearlitic lamellar microstructure or second microstructural level. Left side: longitudinal sections. Right side: transverse sections.

of packing is observed in the lamellae, with decrease of the interlamellar spacing. As in the case of the pearlite colonies, a progressive orientation of the pearlitic lamellar microstructure in the cold drawing direction (wire axis) can be seen seen in the longitudinal metallographic sections, whereas the transverse sections show a randomly-oriented appearance at all stages .

Therefore, both the pearlite colonies and the pearlitic lamellar microstructure tend to align to a direction quasi-parallel to the wire axis as cold drawing proceeds, thus inducing a progressive strength anisotropy in the steel, the degree of anisotropy being an increasing function of the level of cold drawing (or strain hardening) in the steels. 


\section{EXPERIMENTAL PROGRAMME}

To relate these microstructural results to the macroscopic SCC behaviour, slow strain rate tests were performed on transversely precracked steel wires immersed in aqueous environment and subjected to axial loading in the direction of the wire axis. The relationship between crack depth and diameter of the rod was $\mathrm{a} / \mathrm{D}=0.30$ for all the diameters. Specimens were precracked by axial fatigue in air and subjected to five fatigue steps, in such a way that the maximum stress intensity factor in the final stage was always $K_{\max }=0.30 \mathrm{~K}_{\mathrm{IC}}$ (where $\mathrm{K}_{\mathrm{IC}}$ is the fracture toughness of the steel). After precracking, samples were placed in a corrosion cell containing aqueous solution of $1 \mathrm{~g} / 1 \mathrm{Ca}(\mathrm{OH})_{2}$ plus $0.1 \mathrm{~g} / \mathrm{HCl}(\mathrm{pH}=12.5)$ to reproduce the alkaline working conditions of prestressing steel surrounded by concrete. The experimental device consisted of a potentiostat and a three-electrode assembly (metallic sample or working electrode, platinum counter-electrode and saturated calomel electrode as the reference one). The applied displacement rate was constant during the tests and proportional to each wire diameter so that the lowest rate was $1.7 \times 10^{-3} \mathrm{~mm} / \mathrm{min}$ for the fully drawn rod (steel 6: $7 \mathrm{~mm}$ diameter) and the highest was $3.0 \times 10^{-3} \mathrm{~mm} / \mathrm{min}$ for the hot rolled bar (steel 0: $12 \mathrm{~mm}$ diameter). Tests were performed at constant electrochemical potential with the two values of $-1200 \mathrm{mV} \mathrm{SCE}$ and -600 $\mathrm{mV}$ vs SCE, the former associated with the cathodic regime of cracking for which the environmental mechanism is hydrogen assisted cracking (HAC), and the latter linked with the anodic regime of cracking for which the environmental mechanism is localised anodic dissolution (LAD), according to previous research on similar steels $/ 10,11$.

\section{CONSEQUENCES OF COLD DRAWING IN SCC BEHAVIOUR}

The experimental results showed a fundamental fact in both HAC and LAD: the SCC behaviour becomes more anisotropic as the degree of cold drawing increases, so a transverse crack tends to change its propagation direction to approach that of the wire axis, and thus a 
mode I growth evolves towards a mixed mode propagation. It may be assumed that the microstructural orientation in drawn steels influences their macroscopic behaviour, so the SCC resistance is a directional property which depends on the microstructural orientation in relation to the cold drawing direction (strength anisotropy with regard to SCC behaviour). This anisotropic SCC behaviour of the drawn steels can be evaluated by means of the fracture profile (topography of the fracture surface) obtained after the stress corrosion tests.

Fig. 3 shows the fracture profile in HAC conditions, where a progressive change in the macroscopic topography as the cold drawing increases was observed in all fracture surfaces. For the lowest (or null) degrees of cold drawing (Fig. 3a) the crack growth develops in mode I in both fatigue precracking and HAC. However, mixed mode crack growth appears from a certain level of cold drawing (Fig. 3b), and is associated with crack deflection which starts just at the tip of the fatigue precrack, i.e., a deviation in the crack growth path - from its initial fatigue propagation way - appears at the very beginning of the hydrogen embrittlement test. In the last stages of cold drawing, not only crack deflection but also crack branching is observed just after the fatigue precrack tip, i.e., there are two pre-damage directions (crack embryos), only one of which becomes the final fracture path. Table 3 gives the characteristics of the fracture profile (deflection angle $\theta$ and step height $h$ ) for HAC.

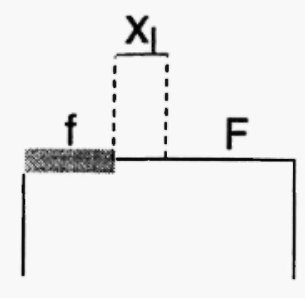

a

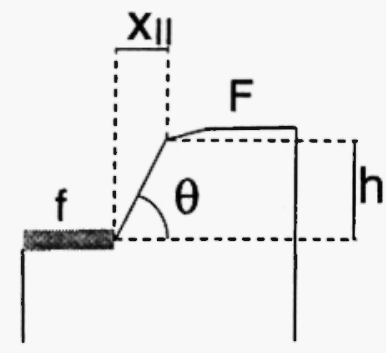

b

Fig. 3. Fracture profile for HAC: (a) slightly drawn steels; (b) heavily drawn steels; f: fatigue crack growth; I: mode I propagation; II: mixed mode propagation; F: final fracture. 
TABLE 3

Characteristics of the fracture profile (HAC).

\begin{tabular}{|c|c|c|c|c|c|c|c|}
\hline Steel & 0 & 1 & 2 & 3 & 4 & 5 & 6 \\
\hline$\theta\left({ }^{\circ}\right)$ & 0 & 0 & 40 & 53 & 70 & 73 & 78 \\
\hline $\mathrm{h}(\mathrm{mm})$ & 0 & 0 & 1.7 & 3.0 & 7.1 & 10.1 & 10.7 \\
\hline
\end{tabular}

The general trends of the fracture profile for LAD are as shown in Fig. 4. For the slightly drawn steels (Fig. 4a), the fracture surfaces were macroscopically plane and oriented perpendicularly to the loading axis, i.e., they develop in mode I, similarly to the case of HAC. In the steels with intermediate and high levels of cold drawing, the macroscopic fracture profile presents three characteristic zones, as sketched in Fig. 4b. After the fatigue precrack there is a first propagation in its own plane (mode I cracking) over a distance $x_{\text {I }}$; after this the crack changes its propagation direction and a mixed mode propagation takes place over a distance $x_{\text {II }}$ (measured as the horizontal projection); finally the crack path follows the original direction up to final fracture. Again not only crack deflection but crack branching is observed in the most heavily drawn steels when the mixed mode propagation appears. The characteristics of the

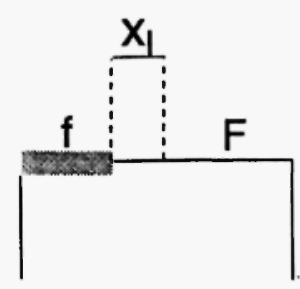

a

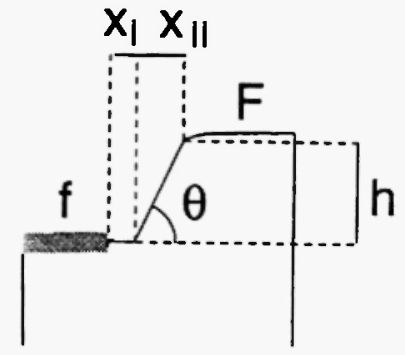

b

Fig. 4. Fracture profile for LAD: (a) slightly drawn steels; (b) heavily drawn steels; f: fatigue crack growth; I: mode I propagation; II: mixed mode propagation; F: final fracture. 
TABLE 4

Characteristics of the fracture profile (LAD).

\begin{tabular}{lccccccc}
\hline Steel & 0 & 1 & 2 & 3 & 4 & 5 & 6 \\
\hline $\mathrm{x}_{\mathrm{l}}(\mathrm{mm})$ & 0.013 & 0.166 & 0.20 & 0.95 & 1.15 & 0.51 & 0.15 \\
$\theta\left({ }^{\circ}\right)$ & 0 & 0 & 0 & 20 & 40 & 60 & 75 \\
$\mathrm{~h}(\mathrm{~mm})$ & 0 & 0 & 0 & 0.92 & 1.07 & 2.18 & 2.58 \\
\hline
\end{tabular}

fracture profile for LAD (mode I propagation distance $\mathrm{x}_{\mathbf{I}}$, deflection angle $\theta$ and step height $h$ ) are given in Table 4.

\section{RELATIONSHIP BETWEEN MICROSTRUCTURE AND MACROSCOPIC SCC BEHAVIOUR}

Fig. 5a shows a plot of the evolution of the orientation angles of the pearlitic colonies and lamellae with cold drawing (angle $\alpha$ between the transverse axis of the wire and the direction marked by the pearlite lamellae in the longitudinal metallographic section; angle $\alpha^{\prime}$ between the transverse axis of the wire and the major axis of the pearlite colony, modelled as an ellipsoid). In both cases there is an increasing trend with cold drawing, i.e., both the pearlite lamellae and colonies become increasingly aligned in the cold drawing direction.

Fig. 5b shows the evolution with cold drawing of macroscopic parameters characteristic of the crack path (fracture profile) in the HAC tests. In the slightly drawn steels the behaviour is isotropic or quasi-isotropic and the macroscopic hydrogen-assisted crack grows in mode I. The steels with an intermediate degree of cold drawing ( 2 and 3) exhibit a slight crack deflection associated with mixed mode propagation. In the most heavily drawn steels the crack deflection is more pronounced and the mixed mode takes place suddenly after the fatigue precrack, the deviation angle and the step height reaching their maximum values. 

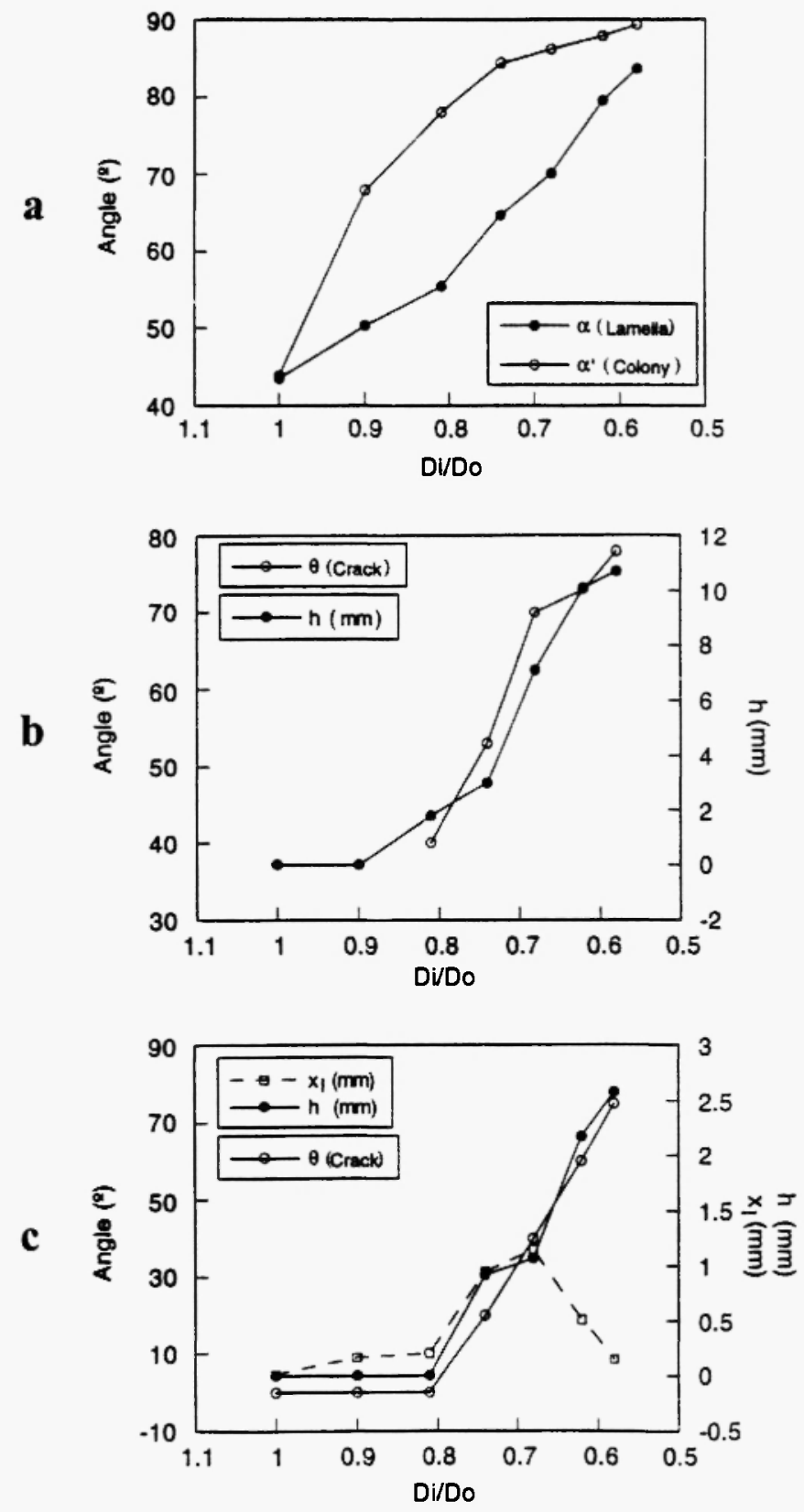

Fig. 5. Relationship between microstructure and macroscopic SCC behaviour: (a) evolution with cold drawing of the orientation angles of colonies and lamellae in the pearlitic microstructure; (b) evolution with cold drawing of the macroscopic crack angle and step height in HAC conditions; (c) evolution with cold drawing of the macroscopic crack angle, step height and mode I propagation distance in LAD conditions; the angles $\alpha, \alpha^{\prime}$ and $\theta$ are measured from the radial direction (transverse to the wire axis). 
Fig. 5c shows the evolution with cold drawing of macroscopic parameters characteristic of the crack path (fracture profile) in the LAD tests. The behaviour is qualitatively similar to that of the HAC tests, i.e., isotropic or quasi-isotropic in the slightly drawn steels and increasingly anisotropic with cold drawing. The important difference is that the material is able to undergo mode I cracking in LAD conditions, even for the heavily drawn steels, although when the crack deflection appears the mode I propagation distance is a decreasing function of the degree of cold drawing (cf. Table 4 and Fig. 5c).

Fig. 5 demonstrates that the progressive microstructural orientation (at the two levels of colonies and lamellae) clearly influences the angle and height of the fracture step (increasing with the degree of cold drawing in both HAC and LAD ) and the mode I distance in LAD (decreasing with it for heavily drawn steels). This change in crack propagation direction can be considered as the signal of the microstructurally-induced anisotropy of these materials: from a certain degree of cold drawing the cracks find propagation directions with lower fracture resistance. This suggests that the macroscopic SCC behaviour of the different steels progressively anisotropic with cold drawing - is a direct consequence of the microstructural evolution towards an oriented arrangement.

\section{CONCLUSIONS}

Results shown in this paper demonstrate that there is a relationship between the evolution with cold drawing of the SCC behaviour of the steels (increasingly anisotropic) and the progressive microstructural orientation induced by the drawing process. The strong plastic deformations produced during manufacture affect the material microstructure and influence the microscopic and macroscopic aspects of the fracture mode in aggressive environments, showing a general evolution from crack propagation in mode I for slightly drawn steels to mixed mode propagation (with strong mode II component) for heavily drawn steels. 
In the two environmentally-assisted cracking regimes (hydrogen assisted cracking and localized anodic dissolution) there is a strong correlation between the microstructural orientation angles (at the two levels of the pearlitic colonies and lamellae) and the propagation angles of the macroscopic crack, which clearly demonstrates the influence of the oriented microstructure and thus of the manufacture process by increasing cold drawing - on the macroscopic SCC behaviour of the steel wires.

\section{Acknowledgements}

The financial support of this work by the Spanish CICYT (Grant MAT97-0442) and Xunta de Galicia (Grants XUGA 11801B95 and XUGA 11802B97) is gratefully acknowledged. In addition, the authors wish to express their gratitude to EMESA TREFILERIA S.A. (La Coruna, Spain) for providing the steel used in the experimental programme.

\section{REFERENCES}

1. PARKINS, R.N., ELICES, M., SANCHEZ-GALVEZ, V. and CABALlERO, L., Environment sensitive cracking of pre-stressing steels. Corros. Sci. 22, 379-405 (1982).

2. KUMRIA, C.C., HARTT, W.H. and KESSLER, R.J., Influence of chlorides, pH and precharging upon embrittlement of cathodically polarized prestressing steel. Proc. Corrosion/90, Las Vegas, Nevada, April 1990 (Paper number 322).

3. ASTIZ, M.A., VAliENTE, A., ELICES, M. and BUI, H.D., Anisotropic fracture behaviour of prestressing steels. In : Life Assessment of Dynamically Loaded Materials and Structures-ECF5 (Edited by L. O. Faria), EMAS, West Midlands, 385-393 (1984).

4. TORIBIO, J., OVEJERO. E. and TOLEDANO, M., Microstructural bases of anisotropic fracture behaviour of heavily drawn steel. Int. J. Fracture 87, L83-L88 (1997).

5. CHERRY, B.W. and PRICE, S.M., Pitting, crevice and stress corrosion cracking studies of cold drawn eutectoid steels. Corros. Sci. 20, 1163-1184 (1980). 
6. SARAFIANOS, N., Environmentally assisted stress-corrosion cracking of high-strength carbon steel patented wire. J. Mater. Sci. Letters 8, 1486-1488 (1989).

7. TORIBIO, J. and LANCHA, A.M., Anisotropic stress-corrosion behaviour of prestressing steel. Materials and Corrosion 49, 34-38 (1998).

8. SAMUELS, L.E. Optical microscopy of carbon steels, ASM, Metals Park, Ohio (1992).

9. VANDER VOORT, G.F. Metallography principles and practice, Mc Graw Hill, New York (1984).

10. TORIBIO, J., LANCHA, A.M. and ELICES, M., Factors influencing stress corrosion cracking of high strength pearlitic steels. Corros. Sci. 35, 521-530 (1993).

11. TORIBIO, J. and LANCHA, A.M., Effect of cold drawing on environmentally assisted cracking of cold-drawn steel. J. Mater. Sci. 31, 6015-6024 (1996). 
